\title{
Standardisation of units for short chain fatty acid production from in vitro fermentation systems
}

\author{
H. Harris ${ }^{1}$, C. A. Edwards ${ }^{1}$ and D. J. Morrison ${ }^{2}$ \\ ${ }^{1}$ Human Nutrition, School of Medicine, University of Glasgow, Yorkhill Hospital, Glasgow, United Kingdom, G3 8SJ \\ and ${ }^{2}$ SUERC, University of Glasgow, East Kilbride, United Kingdom, G75 OQF
}

Short chain fatty acids (SCFA) acetate, propionate and butyrate are produced by colonic bacterial fermentation of non-digestible carbohydrates (NDC). The discovery of free fatty acid receptors (FFAR2 and FFAR3) in the colon, for which SCFA appear to be the natural ligands, has renewed interest in colonic SCFA production. These receptors have potential roles in nutrient sensing, satiety and immune response. The affinity of each receptor for individual SCFA is not equal and varies between receptors ${ }^{(1)}$. In the absence of an in vivo method to measure SCFA production, in vitro fermentation techniques are often used to assess production from different substrates. However, presentation of in vitro data, with highly varied methodology and units of measurement, does not facilitate identification of carbohydrates which selectively promote individual SCFA for use in human studies.

We carried out a literature search of 'in vitro colonic fermentation' to explore the variability of in vitro SCFA production from different NDC and now propose a new unit (rate unit) which allows comparison of studies and more realistically reflects SCFA production in the human colon. In 25 published studies, units used to present data included $\mu \mathrm{mol} / 50 \mathrm{mg}$ carbohydrate, $\mathrm{mmol} / \mathrm{g}$ substrate, $\mathrm{mmol} / \mathrm{L}$, and $\mathrm{mmol} / \mathrm{g}$ organic matter $(\mathrm{OM})$. Data was also presented simply as a ratio. There were variations in the mass of substrate used $(10$ to $2000 \mathrm{mg}$ ) and culture volume (1 to $310 \mathrm{ml})$. Initially, calculations were made to convert the data to one unit (mmol/L), where possible $(n=18)$, using information included in each paper. The rate unit was calculated to take into account volume of culture and amount of substrate.

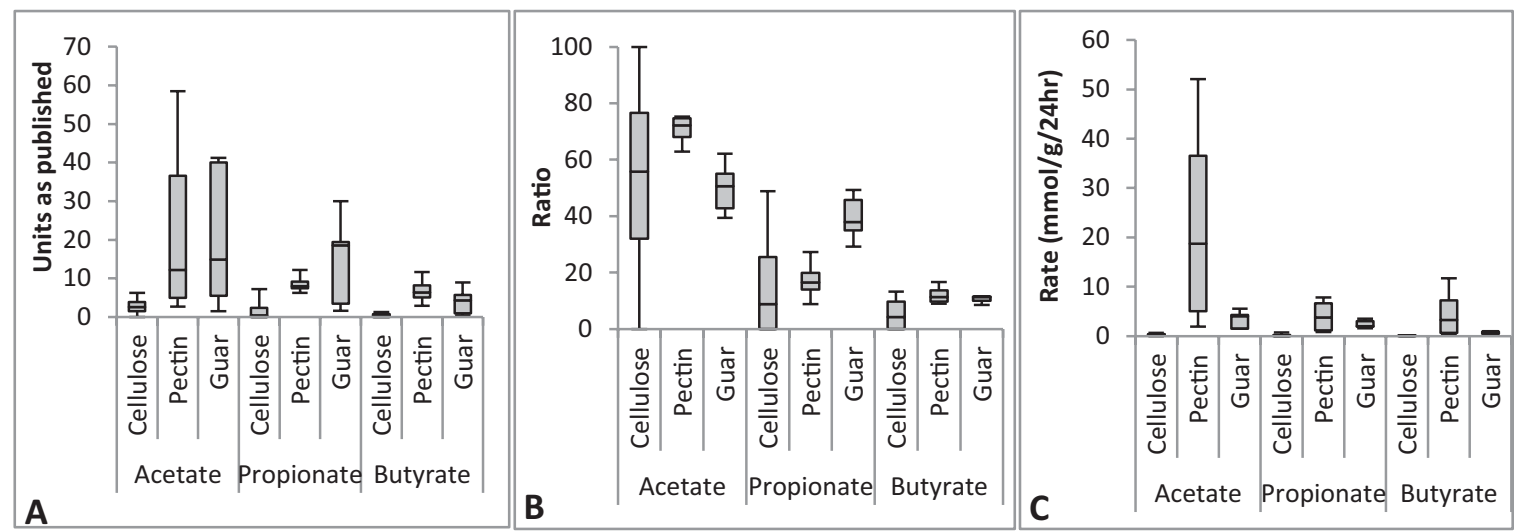

Fig. 1. Box plots (median, interquartile range and minimum/maximum) of in vitro SCFA data as published (A), recalculated as a ratio (B) and presented in a unit of rate of production $(\mathrm{mmols} / \mathrm{g} / 24 \mathrm{hr} ; \mathbf{C})$.

Published data are highly variable and incomparable because of the range of units used or lack of methodological detail. Relying on molar ratios can be misleading because they do not take account of the amount of SCFA produced for each unit of carbohydrate fermented. Establishing a rate term unifies the published data whilst normalising for substrate quantity and vessel volume. We suggest that all in vitro data should provide this information to allow for carbohydrate selection for studies on colonic receptors and which is more likely to reflect production and receptor exposure to SCFA in the human.

1. Lin HV, Frassetto A, Kowalik EJ Jr, et al. (2012) PLoS One 7(4). 